\title{
Editorial
}

\section{Dentistry - At the Heart of Conflict between Medicine and Technology}

\section{Claude Jaquiery}

Department of Cranio-Maxillofacial Surgery and Hightech Research Center, University Hospital Basel, Spitalstrasse 21, 4031 Basel, Switzerland; E-Mail: jaquieryc@uhbs.ch; Tel.: +41-61-265-7233; Fax: +41-61-265-7298

Received: 8 June 2012 / Accepted: 19 June 2012 / Published: 19 June 2012

As the first Editor-in-Chief of Dentistry Journal, I would like to provide a few comments about this field of research and practice. Evolved from a purely technical profession, dentists are nowadays exposed to a variety of different challenges.

The rapidly progressing imaging technology allows improved three dimensional insights within the complex anatomy of the stomatognathic system. As compared to conventional computed tomography, digital volume tomography (DVT) offers enhanced resolution with markedly reduced exposure rate [1]. The targeted volume is still limited, but most pathological entities within the stomatognathic system can be sufficiently visualized. Computer based intraoral scanning methods allow precise depiction of teeth related demarcation lines [2]. Acquired data will be further processed and are used to print synthetic models by rapid manufacturing techniques. The precision of these models is comparable to those produced by conventional impression techniques. Clinical studies to prove the reliability and the efficiency of the system are on-going. Finally, invasive laser systems are more and more involved both in diagnosis and treatment of stomatological pathologies $\left(\mathrm{CO}_{2}\right.$ lasers), as well as the treatment of cavities (erbium-yag lasers) [3]. They allow a safe and clean resection (minimized bleeding) of mucosal lesions. Removal of cavities, in particular in children, may be associated with less pain and discomfort. Critically analyzed and reasonably indicated, many patients may benefit from these new technologies.

However, this remarkable technological evolution has to be developed with an eye to the changing population of dental patients.

In the near future, dentists will be faced with markedly more elderly patients. It is confirmed that these patients often have multiple diagnoses [4], which require a specific action before starting dental treatment. Most common are ischemic diseases affecting the vascular system, in particular coronary arteries. Increasingly more patients benefit from stent implantation due to ischemic heart disease. However, after interventional dilation and subsequent stenting of coronary arteries, a combined medication of aspirin and clopidrogel (Plavix $®$ ) for up to twelve months is in general required [5]. 
These patients are at risk of bleeding during and after dental surgery unless one of these two antiplatelet drugs is stopped seven days before the intervention. As a consequence, the need for dental surgery should be clearly communicated to the treating physician and the modification of the antiplatelet medication evaluated in discussion. In my opinion, it is therefore most important that dentists are informed about new medical treatment modalities in order to be able to competently discuss dental treatment-related problems with the medical specialist. Despite technological progress, dentistry is primarily concerned with patients having dental and medical problems.

I hope that Dentistry Journal will become a venue for the rapid and affordable publication of manuscripts dealing with the technological progress of the specialty, thereby keeping in mind the medical context in which these techniques are performed. Specific attention will be paid to dental treatment of medically severely affected patients.

\section{References}

1. Ziegler, C.M.; Woertche, R.; Brief, J.; Hassfeld, S. Clinical indications for digital volume tomography in oral and maxillofacial surgery. Dentomaxillofac. Radiol. 2002, 31, 126-130.

2. Kurbad, A. Impression-free production techniques. Int. J. Comput. Dent. 2011, 14, 59-66.

3. Olivi, G.; Genovese, M.D.; Caprioglio, C. Evidence-based dentistry on laser paediatric dentistry: Review and outlook. Eur. J. Paediatr. Dent. 2009, 10, 29-40.

4. Kirchberger, I.; Meisinger, Ch.; Heier, M.; Zimmermann, A.K.; Thorand, B.; Autenrieth, Ch.; Peters, A.; Ladwig, K.H.; Döring, A. Patterns of multimorbidity in the aged population. Results from the KORA-Age study. PLoS One 2012, 7, e30556.

5. Reaume, K.T.; Regal, R.E.; Dorsch, M.P. Indications for dual antiplatelet therapy with aspirin and clopidrogel: Evidence-based recommendations for use. Ann. Pharmacother. 2008, 42, 550-557.

(C) 2013 by the authors; licensee MDPI, Basel, Switzerland. This article is an open access article distributed under the terms and conditions of the Creative Commons Attribution license (http://creativecommons.org/licenses/by/3.0/). 